\title{
Mini Review
}

\section{Current Scenario and Future Perspectives of CPV-2 Vaccines in India}

\section{Kamal Hasan ${ }^{1}$, Doddamane Rathnamma ${ }^{1}$, Hogalagere Doddappaiah Narayanaswamy ${ }^{2}$, Venkataramaiaha Malathi ${ }^{2}$, Neelam Tomar ${ }^{3}$, Saurabh Gupta ${ }^{4}$, ShoorVir Singh ${ }^{4}$}

\begin{abstract}
${ }^{1}$ Department of Veterinary Microbiology, Veterinary College, Hebbal, Karnataka Veterinary Animal and Fisheries Sciences University (KVAFSU), Bengaluru-560024; ${ }^{2}$ Department of Pathology, Veterinary College, Hebbal, Karnataka Veterinary Animal and Fisheries Sciences University (KVAFSU), Bengaluru-24; ${ }^{3}$ Indian Veterinary Research Institute, Izatnagar,Bareilly ; ${ }^{4}$ Division of Animal Health, Central Institute for Research on Goats (CIRG), Makhdoom, PO-Farah, Mathura-281122, Uttar Pradesh, India.
\end{abstract}

\begin{abstract}
Canine parvovirus causes acute hemorrhagic gastroenteritis in canines. It is prone to genetic evolution and has undergone several mutations that have led to various antigenic variants of CPV-2.Vaccination is the most cost-effective and ideal method to control the canine parvovirus infections. Both live attenuated and inactivated vaccines are available to control the disease in animals. Vaccines used during the late 1970s and early 1980s were of feline panleukopenia virus (FPV) origin, which was followed by the use of inactivated and live attenuated vaccines of CPV-2 canine origin. Hightiter and low-passage CPV vaccines containing a canine-origin attenuated virus are currently considered vaccines-ofchoice for use in pups of any breed. Vaccination is likely to be successful when the maternal antibody titer has declined to less than 1:10. Titers below 1:40 are variably protective, but they may interfere with vaccination. Strain difference between field virus and vaccine candidate virus could be one of the important attributable reasons for immunization failure in the country. The high rate of infection in both vaccinated and unvaccinated dogs raise questions on relevance of the present day vaccines, which in most countries contain old variants. Though some believe that the heterologous protection offered by these old strains against the new variants is good enough, a growing proportion think that the time has come to manufacture vaccines incorporating the variants prevalent in a country.
\end{abstract}

Keywords | Canine parvovirus, Vaccination failure, Variants, Live attenuated, Inactivated vaccines

Editor | Kuldeep Dhama, Indian Veterinary Research Institute, Uttar Pradesh, India.

Received | May 22, 2017; Accepted | August 18, 2017; Published | October 15, 2017

*Correspondence | Shoor Vir Singh, Division of Animal Health, Central Institute for Research on Goats (CIRG), Makhdoom, PO-Farah, Mathura-281122, Uttar Pradesh, India; Email: shoorvir.singh@gmail.com

Citation | Hasan K, Rathnamma D, Narayanaswamy HD, Malathi V, Tomar N, Gupta S, Singh SV (2017). Current scenario and future perspectives of cpv-2 vaccines in india. Adv. Anim. Vet. Sci. 5(11): 446-448.

DOI | http://dx.doi.org/10.17582/journal.aavs/2017/5.11.446.448

ISSN (Online) | 2307-8316; ISSN (Print) | 2309-3331

Copyright $(2017$ Kamal-Hasan et al. This is an open access article distributed under the Creative Commons Attribution License, which permits unrestricted use, distribution, and reproduction in any medium, provided the original work is properly cited.

\section{INTRODUCTION}

$\mathrm{C}$ anine parvovirus-2 (CPV-2) emerged in 1978 as the etiological agent of haemorrhaghic gastroenteritis of dogs characterized by loss of appetite, vomiting and leucopenia (Appel et al., 1979) The disease condition has been dreadful further due to emergence of a number of variants namely CPV-2a, CPV-2b, CPV-2c, New CPV- 2a, New $\mathrm{CPV}-2 \mathrm{~b}$ and involvement of domestic and wild canines. The prevalence of CPV-2a and New CPV-2a has been documented in Southern India. In North India, the prevalence of CPV-2b is more compared to the other mutants. Occurrence of CPV-2c was first reported in India based on the sequence analysis of a CPV-2b positive sample. Its antigenicity of the $\mathrm{CPV}$ variants as it is located in the presence in India supports the assumption that CPV-2c is going to reach a worldwide distribution and provides new informa- tion to understand the evolution of antigenic used for the detection of some of the mutants of CPV-2. Routine diagnostic methods include electron microscopy (EM), virus isolation (VI), hemagglutination (HA), radial haemolysis test, serum neutralizing antibody, immunochromatography (IC), enzyme linked immuno-sorbent Assay (ELISA), latex agglutination test, immune-fluorescence, immuno-peroxidase, insitu hybridization. co-agglutination test, polymerase chain reaction (PCR), real time PCR, Multiplex real-time PCR. In parvoviral gastroenteritis cases, conventional live attenuated vaccines are being used to vaccinate small animals. This article is aimed to provide detailed information about different causes of vaccine failure and the best ways to control the disease.

\section{INDIAN SCENARIO}

In India, the first report of occurrence of CPV-2 dates back 
to 1982 by Ramadass and Khader, (1982). Since then, the incidence of CPV-2 variants in dogs were reported from different states viz. Kerala, Orissa, Assam, West Bengal, Tamil Nadu, Pondicherry, Haryana and Uttar Pradesh. Occurrence of CPV-2c was first reported in India based on the sequence analysis of a CPV-2b positive sample by Nandi et al. (2010). Later, the outbreak of CPV-2c in vaccinated dogs in Anand district of Gujarat was reported by Gauri and colleagues in 2013.

\section{Recent Diagnostic Techniques}

Recently, A quartz crystal microbalance (QCM) biosensor was developed for rapid detection of CPV infection using prolinker $^{\mathrm{TM}} \mathrm{B}$. ProLinker ${ }^{\mathrm{TM}} \mathrm{B}$ enables antibodies to be attached to a gold-coated quartz surface in a regular pattern and in the correct orientation for antigen binding. QCM biosensor was $95.4 \%$ sensitive and $98 \%$ specific compared to PCR. It is rapid and accurate clinical diagnostic tool for CPV infection (Kim et al., 2015).

Loop mediated isothermal amplification (LAMP) with enzyme-linked immunosorbent assay (LAMP-ELISA) and with lateral flow dipstick (LAMP-LFD) are found to be rapid, sensitive and specific methods for the visual detection of clinical pathogen ( $\mathrm{Yu}$-Ling et al.2013).To differentiate canine and feline parvovirus in serum and faecal samples, Taq-Man PCR was developed (Streck et al., 2013).

MicroRNA expression analysis was developed to understand the molecular basis of FPV and CPV infection in cats. MicroRNAs being involved in virus-host interactions might provide us with an alternative strategy for disease prevention and control, like developing the direct antiviral effects, and stimulating the antiviral innate immune responses to virus infection (Zhou et al., 2017).

Peptide nucleic acid-based (PNA) array are considered as a stable nucleic acid analogue. Peptide nucleic acid-based (PNA) array was used to discriminate between the four CPV-2 antigenic types (CPV-2, -2a,-2b, and -2c) during ante-mortem diagnosis of dogs, using newly developed PNADNA hybridization assay. The PNA array has high sensitivity and specificity compared with a real time PCR using the TaqMan assay, a gold standard method (An et al.,2012).

Next-generation sequencing (NGS) methodologies was developed by targeting RNA transcripts, and therefore detecting only replicating virus. Using the data generated by NGS, the presence of newly evolved, yet known, strains of both CPV-2a and CPV-2b were identified and grouped geographically. Deep-sequencing data provided additional diagnostic information in terms of investigating novel CPV. NGS data in addition to limited serological data provides strong diagnostic evidence that the outbreaks were most likely arose from unvaccinated or under-vaccinated canines, not from a novel CPV strain incapable of being neutralized by current vaccination efforts (Parker et al.,2017).

\section{Cross Protection among CpV-2 Variants}

With an increasing number of cases of the current vaccines against this mutant is another question that must be addressed. In an experimental study, using the Neutralization test, the pups inoculated with CPV-2 had antibody titers, which were approximately 30 times higher to homologous virus than to heterologous virus (CPV-2 b). There is only one report which shows of sick dogs showing symptoms suggestive of CPV, including vaccinated animals, raises concerns among breeders, owners and veterinary practitioners about the ability of the current vaccines to protect the pups, as noted previously in other countries (Decaro et al., 2008) The efficiency complete protection against type $2 c$ by an attenuated vaccine based on other CPV type. On the other hand, there are several works reporting vaccine failures when the challenge virus is of the type $2 \mathrm{c}$ (Decaro et al., 2008). In order to obtain better protection against the field strains of CPV, the incorporation of a specific new variant of $\mathrm{CPV}-2$ in the vaccine is recommended based on the prevalence in the country.

\section{Canine Parvovirus Vaccines}

Initially, killed CPV vaccine was used and in recently modified live vaccine have been developed in search of improved potency. Inactivated vaccines, however, provide only a short immunity to the infection. Although dogs may be protected for several months against disease, they may have subclinical infection. Modified live vaccine offers a longer duration of immunity than killed vaccine. Vaccination against CPV may not provide immunity, because vaccine is based on CPV 2 but outbreak strains are of CPV $2 \mathrm{a}$ and $2 \mathrm{~b}$, now $2 \mathrm{c}$ is also prevalent. The $\mathrm{HI}$ test is used to measure antibodies. HI titre 1:80 or more is considered protective (Khatri et al., 2017). Vaccination of dogs is generally performed using multivalent vaccines, which contain CDV, CPV, leptospira bacteria and inactivated rabies virus. Monovalent CPV-2 vaccines are also available, some of them containing very high titer virus $\left(10^{7} \mathrm{TCID} 50\right)$ and widely recommended for initial vaccination of pups.

\section{Causes of Vaccination Failure}

1) Improper vaccination schedule by pet owners

2) Mismatching of vaccine strain with field strain prevailing in the outbreak area.

3) Interfering level of maternally derived antibodies

4) Allowing the pet with stray dog

5) Lack of disinfection in the premises

6) Lack of awareness of vaccination

7) Importing of dog lacking vaccination history.

Strategies for reducing/overcoming risk of maternal interference include biweekly vaccination and low passage, high titer vaccines.

\section{Current Vaccines Available in India}

Manufacturers of the vaccine puppy shot are commonly used including:

1) Nobivac DHPPi and Nobivac ${ }^{\circledast}$ Puppy DP Vaccine -strain C 154

2) CANIGEN DHPPi/L Vaccine -Cornell strain

3) Mega Vac-6 Vaccine - Attenuated Parvovirus of canine origin.

Adequate CPV vaccination was defined as completed primary vaccination series, including $\mathrm{MLV}$ at a 3-4 week interval with the last vaccination at a minimum of $14-16$ 
weeks of age, a booster vaccination 11-13 months later, and subsequent revaccinations at a minimum of 3-yearly (Welborn et al., 2011).

\section{Alternate Vaccines}

\section{Recombinant vaccine}

Recombinant vaccine containing the baculo virus expressed VP2 protein was found to be structurally and immunologically indistinguishable from authentic. Recombinant VP2 also shows the capability to self assemble, forming virus-like particles similar in size and appearance to CPV virions. The use of these VLPs as vaccines, doses containing only $10 \mathrm{ug}$ of protein were able to elicit neutralizing antibodies and IHA titers sufficient to render all of the immunized animals protected. VP2 is the main determinant of the neutralization-specific immune response in CPV and that it is able to induce protection (Jose et al., 1992).

\section{DNA vaccine}

Recombinant plasmid pTargeT.cpvp2 was used to transfect CRFK cells and found to express VP2 protein as detected by immuno peroxidase test. It was used as DNA vaccine in dog by injecting as $100 \mathrm{ug}$ DNA with and without adjuvant. Continuous expression of CPV viral antigen that is characteristic of DNA vaccine results in better immune response than recombinant vaccine, which delivers only a single pulse of antigen and requires multiple doses to achieve protection and expresses the entire antigenic viral protein in its native form, thus providing better stimulation of the immune system (Gupta et al., 2005).

\section{Peptide vaccine}

A vaccine dose contained a mixture of $1 \mathrm{mg}$ of peptide IL15 and $1 \mathrm{mg}$ of peptide 7L15, were used (Langeveld et al.,1994). An advantage of the peptide vaccine is the possibility of designing tests, which discriminate between vaccinated and infected animals. With the HI test, animals, which had been infected with virus, could be distinguished from vaccinated animals before experimental infection. Alternative tests could obviously be developed, as is evident from the blocking experiments, in which antibody binding could be inhibited by the peptides used for vaccination only in the sera taken before sero conversion. Such discriminatory tests are useful in programs to eradicate pathogenic viruses like that applied with the veterinary marker vaccine for pseudo rabies virus infection in swine. They can also be of importance in the surveillance of the occurrence of a virus, for which vaccination with peptides might become available.

\section{CONCLUSIONS}

Incorporating the field strains in the vaccines will help in conferring complete protection in canines and alternate vaccines using recombinant technology has to be developed apart from conventional vaccines to overcome the emergence of new variants and to reduce the vaccine failure.

\section{ACKNOWLEGEMENTS}

Authors are thankful to Dr. Rathnamma, Professor and Head and Dr. Malathi V. Associate Professor for their support.

\section{CONFLIC'T OF INTEREST}

We declare that we have no conflict of interest.

\section{AUTHORS CONTRIBUTION}

All authors contributed equally.

\section{REFERENCES}

-An DJ, Jeong W, Jeoung HY, Lee MH, Park JY, Lim JA, Park BK (2012). peptide nucleic acid based array for the antigenic discrimination of canine parvovirus. Res. Vet. Sci. 93:515-519.

-Appel MJG, Scott FW, Carmichael LE (1979). Isolation and immunization studies of a canine parvo-like virus from dogs. Vet. Rec. 105: 156-159. https://doi.org/10.1136/vr.105.8.156

- Decaro N, Desario C, Elia G, Martella V, Buonavoglia C (2008) . Evidence for immunization failure in vaccinated adult dogs infected with canine parvovirus type 2c. New Microbiol. 31: 125-130.

- Gauri DM, Jhala MK, Joshi CG (2013). Genotyping of canine parvovirus by PCR and RFLP. Int. J. Adv. Biol. Res. 2: 246248

- Gupta PK, A Raut, Chauhan S (2005). Cloning of canine parvovirus VP2 gene and its use as DNA vaccine in dog. Current Sci. 88: 5-10.

-Jose angel Lopez de turiso, Elena cortes, Concepcion Martinez, and Ignacio casall (1992). Recombinant Vaccine for Canine Parvovirus in Dogs. J. Virol. $66: 2748-2753$.

-Kim YK, Seong-In L, Sarah C, Eun-Hye P, Dong-Jun A (2015). A novel assay for detecting canine parvovirus using a quartz crystal microbalance biosensor. J. Virol. Method. 219: 23-27.

-Khatri R, Poonam, Mohan H, Minakshi, Pundir CS (2017). Epidemiology, pathogenesis, diagnosis and treatment of canine parvovirus disease in dogs: A mini review abstract. J. Vet. Sci. Med. Diagn. 6:3.

- Langeveld PM, J Ignacio casal, Albert DM, Rob H (1994). First Peptide Vaccine Providing Protection against Viral Infection in the Target Animal: Studies of Canine Parvovirus in Dogs. J. Virol. 68: 4506-451.

- Nandi S, Anbazhagan R, Kumar M, Chauhan RS (2009). Molecular Characterization of Canine parvovirus strains in vaccines by polymerase chain reaction and restriction endonuclease analysis. Indian J. Virol. 5: 12-15.

-Nandi S, Kumar M, Chidri S, Chauhan RS (2008). Current status of Canine parvovirus infection in dogs in India and its pathogenesis. Indian J. Vet. Pathol. 32(2): 150-157.

- Nandi S, Chidri S, Kumar M, Chauhan RS (2010).Occurrence of Canine parvovirus type $2 \mathrm{c}$ in the dogs with haemorrhagic enteritis in India. Res. Vet. Sci. 88: 169-171.

-Parker J, Murphy M, Hueffer K, Chen J (2017). Investigation of a canine parvovirus outbreak using next generation sequencing. Sci. Reports. 7.

- Ramdas P, Khader TG (1982). Diagnosis of Canine parvovirus infection by agar gel precipitation test and fluorescent antibody techniques. Cherion. $11: 323-328$.

-Streck D, Truyen U, Homeier T (2013). An updated Taq-Man real-time PCR for canine and feline parvoviruses. J. Virol. Method. 193: 6-8.

-Welborn LV, Deries JG, Hurley KF, McClure KD, Schultz, RD (2011). AAHA canine vaccination guidelines. J. Am. Anim. Hospital Assoc. $47: 1-42$.

-Zhou P, Zhang X, Zheng W, Hao X, Lin X, Zheng Y, Wang L, Zhang G, Li S (2017). MicroRNA expression analysis of feline and canine parvovirus infection in vivo (felis). Plos one. 12. 